\title{
VALORACIÓN DEL PATRIMONIO CULTURAL ASOCIADO CON EL BARNIZ DE PASTO MOPA-MOPA, A PARTIR DE LA PARTICIPACIÓN CIUDADANA
}

\section{Entorno Cultura}

Germán Alonso Arturo Insuasty

germanarturo@udenar.edu.co

Universidad de Nariño

Pasto, Nariño.

Apropiación sociocultural, barniz de Pasto,

Palabras Clave: participación ciudadana, patrimonio cultural, plan

de salvaguardia. 


\section{Resumen}

El artículo presenta los resultados de investigación sobre la valoración del Patrimonio

C Cultural asociado con el Barniz de Pasto (Mopa-Mopa), a partir de testimonios escritos y visuales obtenidos de manera participativa. La investigación fue de orden cualitativo, con un tipo diagnóstico-propositivo de corte etnográfico. La muestra fue de 198 personas con un rango de edad entre los 18 y 70 años. El trabajo de campo se realizó en la ciudad de Pasto (Colombia), con la participación de un taller artesanal como piloto de la investigación, en el que trabajan dos maestros artesanos, caracterizados por ser padre e hijo y estar dentro de la artesanía de referencia cultural enfocada a la salvaguardia de la técnica. Con esto se pretendió comprender las problemáticas de este segmento de artesanos en su contexto, donde se identificó una insuficiente apropiación sociocultural de las actividades artesanales por parte de los ciudadanos de Pasto. En el artículo se reflexiona sobre el concepto de valor patrimonial y algunas acciones realizadas para la salvaguardia de la técnica; luego se presentan los hallazgos y las etapas del proceso para realizar la intervención propuesta, para contrastar los testimonios encontrados como parte de la metodología de valoración. Se propone una plataforma web participativa y abierta para visualización de artesanías de Barniz de Pasto.

\section{Problema}

Los conocimientos y técnicas tradicionales asociadas con el Barniz de Pasto (Mopa-Mopa), se incluyeron en el 2019 en la Lista Representativa de Patrimonio Cultural Inmaterial (LRPCI) de Colombia (Ministerio de Cultura, 2019a). Esta es la tercera manifestación patrimonial de la ciudad de Pasto reconocida para su salvaguardia, después del Centro Histórico de la ciudad, declarado Patrimonio Histórico y Artístico Nacional en 1959, y del Carnaval de Negros y Blancos declarado Patrimonio Cultural Inmaterial de la Humanidad en el año 2009 por parte de la Organización de las Naciones Unidas para la Educación, la Ciencia y la Cultura (UNESCO).

Esta inclusión en la lista permite consolidar el fortalecimiento de la actividad artesanal, así como la puesta en marcha del Plan de Salvaguardia, el cual aporta significativamente en la preservación de los conocimientos y técnicas artesanales. En ese sentido, motiva a los artesanos a que sigan fabricando sus productos, transmitan sus conocimientos y continúen teniendo una influencia positiva en la comunidad nariñense.

A pesar de ser una técnica ancestral y reconocida, no es ajena a las dinámicas económicas propias de la globalización, las cuales generan grandes dificultades para que las técnicas tradicionales como la artesanía sobrevivan en los mercados locales, pues la producción industrial en serie permite desarrollar productos con menores precios y tiempos, creando mercados fuertemente estandarizados que compiten con las artesanías hechas a mano. 
Precisamente, otra de las características de la globalización es la creación de mercados masivos y homogéneos fuertemente estandarizados en términos de cultura, que suponen altos volúmenes de producción a precios bajos; de hecho, el consumo se constituye en un elemento clave que permite mantener todo el entramado de producción-distribución-comercio. (Serrano Neira, 2015, p. 61)

Como sucede en diferentes lugares del mundo, por varios años los artesanos del Barniz de Pasto trabajaron de manera individual en sus talleres artesanales sin integrarse como gremio. Estrada Álava, Rivera Vallejo, Goyes Eraso y Bastidas Mera (2008) aseguran que se observa una tendencia a trabajar individualmente y no asociarse. De esta forma, aunque los artesanos barnizadores son expertos en la transformación de la materia prima del Barniz de Pasto (la planta del mopa-mopa) y aplicarla en piezas decorativas hechas en madera, dependen, principalmente, de la comercialización de sus productos, pues su tendencia es hacia la ocupación exclusiva al oficio. El 73\% de los artesanos del Barniz de Pasto se dedican únicamente a producir esta artesanía (Estrada Alava et al., 2008). Una de las consecuencias del trabajo individual es que existe una alta incidencia de los intermediarios en el precio de compra y venta de los productos en los diferentes mercados. Esto desencadena en un acceso restringido a mercados basados en comercio justo.

Por otra parte, la información sobre cómo se transforma el mopa-mopa para ser aplicado en artesanías de Barniz de Pasto, continúa siendo, en muchos casos, un secreto del oficio, al cual es difícil acceder si no se tiene consanguinidad, como consta en el Plan Especial de Salvaguardia (PES), en lo referente a conocimientos y técnicas tradicionales asociadas con el Barniz de Pasto Mopa-Mopa, en Putumayo y Nariño (Mincultura, 2019b): “Los artesanos que aprendieron como obreros consideran que, por el hecho de no tener el lazo consanguíneo, no se favorecieron de los secretos de la técnica desarrollada por los maestros, los cuales estaban reservados para los familiares” (p.23). En el mismo documento se señala: “De ahí que el maestro sienta la necesidad de conservar en secreto las experimentaciones, en la medida que los conocimientos son guardados celosamente, incluso, a ellos no pueden acceder los aprendices y oficiales" (p.21).

De esta forma, es probable que esto hiciera que pocas personas de la comunidad no artesanal tuvieran el interés por aprender más sobre la técnica. La información cerrada trae como consecuencia que la comunidad tenga un limitado conocimiento de la elaboración y producción de las técnicas creativas y artesanales a nivel local, lo cual se evidencia en el PES: “En su gran mayoría, los habitantes del municipio de Pasto desconocen el proceso que se debe realizar para llegar a la pieza decorada de Barniz de Pasto" (p.41). Este desconocimiento generalizado hace que sea insuficiente el reconocimiento social a las actividades creativas y artesanales, de tal forma que sea complejo incrementar el valor económico recibido por sus productos. La falta de reconocimiento local de los actores que intervienen en el proceso, sean estos recolectores, artesanos de la madera y barnizadores, se hace evidente como problemática a intervenir dentro del PES (Mincultura, 2019b), en cuanto a la valoración, apropiación social y difusión. La poca valoración del trabajo creativo y artesanal está ligada con el bajo precio que el habitante de Pasto está dispuesto a pagar y la gran dificultad del artesano o artesana para vender sus productos a precios justos. 
Esta desconexión entre la comunidad, las instituciones y los artesanos y artesanas hace que se desarrolle un proceso de comunicación deficiente, que no permite aumentar los niveles de confianza en su relacionamiento, teniendo así una limitada capacidad para reconocer nuevos talentos y una baja valorización positiva desde los ciudadanos. Por lo tanto, la aceptación y valoración positiva de las artesanías se robustece mediante el mejoramiento el conocimiento, a partir de investigaciones serias (Malo, 2016, p. 20).

En este contexto, es necesario fomentar la apropiación ciudadana del Barniz de Pasto como patrimonio, de tal forma que se propicien espacios para incrementar el valor social del artesano, permitiendo así que prosperen los espacios socioculturales en torno a los saberes, conocimientos y técnicas del Barniz de Pasto y, por ende, se incentive el consumo local de estos productos. Así, surge la siguiente pregunta-problema: ¿Cómo podrían los ciudadanos de Pasto, fortalecer los procesos participativos de apropiación social de la técnica del Barniz de Pasto?

\section{Propuesta Creativa}

\section{- Marco teórico}

\section{Valoración artesanal}

En la propuesta metodológica para la valoración participativa de testimonios de museos y entidades culturales en Colombia, se plantea que la primera condición para hacer un ejercicio de valoración es entender que se deben seguir un conjunto de pasos para determinar las cualidades de los objetos. En esta búsqueda están involucrados tres factores: el objeto o manifestación, el sujeto y el contexto (Bastidas \& Vargas, 2013, p. 25).

Al respecto Bastidas y Vargas (2013) afirman:

En el momento en que se tiene al objeto o manifestación, que posee un tipo de cualidades, y un sujeto o comunidad que determinan esas cualidades particulares, hay que entender que se hace dentro de un contexto, es decir, las personas y el patrimonio están influenciadas por el lugar y el tiempo en los que se encuentran con tradiciones, gustos, modas, intereses políticos, intereses sociales, intereses particulares, etc.

Otro factor importante de comprender del contexto es que es preciso definir el lugar donde se encuentra el patrimonio a valorar actualmente, pero también que, en diferentes momentos de la historia, ese mismo patrimonio se ha encontrado en uno o más lugares, y también ha tenido distintos significados para varias sociedades. (pp. 23-26)

Dentro de esta metodología, las autoras proponen también que:

El valor cultural del patrimonio es la suma de las cualidades intrínsecas de un testimonio, y todas aquellas cualidades que las personas pueden ver en él. Se debe tener en cuenta que el patrimonio cultural se compone de manifestaciones materiales e inmateriales; por lo tanto, el término testimonio se referirá tanto a objetos como a manifestaciones inmateriales. 
Y además dicen: "Las cualidades o valores de un testimonio lo hacen importante para un grupo o varios grupos de personas interesadas en él, por eso lo reconocen y ejercen acciones para protegerlo y conservarlo para el disfrute de futuras generaciones" (p.44).

Por lo tanto, recopilar testimonios de los ciudadanos se hace relevante para comprender el valor cultural del patrimonio de las artesanías locales desde una visión contemporánea. EI interrogarse por el sentido actual de artesanías tradicionales como la del Barniz de Pasto, permite de una u otra forma reconstruir su significado dentro de un contexto patrimonial a partir de la participación ciudadana.

David Throsby (2000) plantea que el valor es multidimensional y está mediado por un rango de características específicas, afirmando que:

First, it is clear that value is multidimensional. So, it may be possible to describe an art work, for example, as providing a range of cultural value characteristics, including:

- aesthetic value: beauty, harmony;

- spiritual value: understanding, enlightenment, insight;

- social value: connection with others, a sense of identity;

- historical value: connection with the past;

- symbolic value: a repository or conveyor of meaning.

[Primero, está claro que el valor es multidimensional. Por lo tanto, puede ser posible describir una obra de arte, por ejemplo, como que proporciona una gama de características de valor cultural, que incluyen:

- el valor estético: belleza y armonía,

- el valor espiritual: comprensión, iluminación y visión,

- el valor social: conexión con otros, un sentido de identidad,

- el valor histórico: conexión con el pasado,

- el valor simbólico: un repositorio o portador de significado]. (p. 29)

Es así como la artesanía produce efectos externos positivos a partir de los valores de existencia, prestigio, opción, educación y legado. Su valor es multidimensional y se rige bajo principios de eficiencia y equidad intergeneracional, como un derecho de las generaciones futuras a la cultura.

La valoración artesanal está ligada no sólo a los ejercicios ciudadanos sino, también, a entidades gubernamentales y privadas que aporten a la preservación de la técnica, como es el caso de Artesanías de Colombia que desde la década del setenta realiza investigaciones y asesorías de diseño, que contribuyen al desarrollo de los procesos productivos en la cadena del Barniz de Pasto. 


\section{Intervención}

Se realizó la propuesta de intervención que incluye dos acciones para cumplir con los objetivos propuestos en la investigación. La primera, está enfocada en visibilizar los resultados del proceso de participación ciudadana y disponer de herramientas de visualización de información para el sector artesanal del Barniz de Pasto. Para esto se diseñó una plataforma digital de visibilización y documentación de las técnicas asociadas al Barniz de Pasto Mopa-Mopa, que constituye un Atlas Artesanal. La segunda, está enfocada en mejorar el conocimiento de la técnica y de las comunidades que llevan a cabo la manifestación del Barniz de Pasto Mopa-Mopa por parte de los ciudadanos de San Juan de Pasto. Para esto se co-creó un taller de aproximación al Barniz de Pasto.

Así, se describe a continuación la intervención:

\section{A. Atlas Artesanal:}

Con la información recopilada, se crearon y consolidaron una serie de mapas que ayudan a la visibilización y documentación participativa de los conocimientos y técnicas artesanales asociadas al Barniz de Pasto Mopa-Mopa, que conforman un Atlas Artesanal en línea denominado mopamopa.info.

Mapa Artesanal del Barniz: los objetos de Barniz de Pasto tienen un valor personal y sentimental para sus propietarios, conservan gran parte de la historia de la técnica y pueden tomarse como testimonios documentales que favorecen la investigación histórica y el fortalecimiento del valor social de los artesanos en la construcción de la identidad regional.

Se realizó una recopilación de imágenes de artesanías realizadas con Barniz de Pasto que se encuentran en los hogares de los ciudadanos, a partir de la cual se identificó en un primer momento si los ciudadanos tienen o no piezas de Barniz de Pasto en sus casas y los lugares de la ciudad donde están estas artesanías. Para la recolección de imágenes se optó por utilizar medios digitales, teniendo en cuenta que, al realizar la invitación de manera análoga, las personas no enviaban las imágenes.

Inicialmente se realizaron preguntas electrónicas a través de Facebook, a personas del círculo de amigos del investigador con el objetivo de identificar quiénes tienen artesanías de Barniz de Pasto. Para tener un mayor alcance, después se envió un correo electrónico desde la cuenta oficial de la Maestría en Diseño para la Innovación Social a todos los correos electrónicos de estudiantes y profesores de la Universidad de Nariño, invitando a participar en el proyecto. Sin embargo, la participación fue baja.

Posteriormente, a través de la página de Facebook del proyecto, se realizó una convocatoria de manera abierta utilizando Facebook ads, donde se solicitó a las personas que tenían artesanías de Barniz que enviaran fotografías para publicarlas en el mapa. 
Por otra parte, el Museo Zambrano envió directamente fotografías de las artesanías que tienen en exhibición. Se visitó el Museo Juan Lorenzo Lucero y el Museo del Oro, para solicitarles que se pudiera documentar las artesanías que ellos poseen con el fin de publicarlas, con inclusión de los créditos de ubicación del lugar.

A mediano y largo plazo se pretende identificar el capital simbólico de cada artesanía y a qué artesano pertenece; también se busca consolidar una memoria gráfica, pública y abierta de la técnica. Las imágenes recopiladas se publicaron en un mapa que hace parte del Atlas Artesanal.

Mapa de Direcciones y Rutas Artesanales: dentro de la investigación se identificó que los ciudadanos no conocen dónde están ubicados los talleres artesanales, no existe en internet un mapa interactivo de ubicación de estas direcciones y tampoco aparecen en google. Se encontró que, en la exposición de Barniz de Pasto realizada en el 2018, se entregó un plegable con la información de los talleres artesanales. Este plegable fue facilitado para la investigación por los maestros artesanos Ever Narváez y Jonathan Narváez; así mismo, la Gobernación de Nariño en su publicación Le tengo el dato No.3, publicó las direcciones de los talleres bajo licencia Creative Commons. Dentro del Atlas se incluye un mapa que posee la información georreferenciada de cada taller artesanal y la información general que aparece en la publicación de la Gobernación de Nariño.

\section{B. Workshop de aproximación al Barniz de Pasto:}

Finalmente, después de analizar con los artesanos el proceso llevado a cabo, manifestaron que uno de sus deseos es crear un workshop de enseñanza de la técnica, al tener en cuenta que en su historia artesanal siempre han estado dispuestos a compartir la técnica del barniz y que han dictado exhibiciones de acercamiento a la misma en el Museo de la Casona Taminango.

Es así como se inició el diseño de una experiencia que pueda ser vendida bajo el concepto de comercio justo y que sirva, por una parte, para dar a conocer la técnica y el taller artesanal Kyrioz; y, por otra, aportar a disminuir el desconocimiento que algunos ciudadanos tienen sobre la actividad artesanal.

De esta manera, se determinó que el workshop estaría dirigido a personas que quisieran conocer más sobre la técnica directamente en un taller artesanal y que, a partir de esta experiencia, valoren más y comprendan mejor el proceso y el tiempo que cada persona de la cadena del Barniz de Pasto dedica a esta actividad. Al tener en cuenta que para ser maestro artesano se requieren varias décadas de aprendizaje para lograr perfeccionar su actividad y pasar de ser obrero, obrera o aprendíz a maestro o maestra, esta experiencia no se diseñó con el fin de iniciar procesos de aprendizaje para convertir a los asistentes en maestros, como puede ocurrir en el caso de los diplomados, capacitaciones o enseñanzas en los talleres artesanales.

Por todo lo anterior se diseñó un kit artesanal de aproximación al Barniz de Pasto, que contiene las herramientas básicas para tener una experiencia guiada por los maestros para realizar una pequeña artesanía de Barniz de Pasto. El kit es réplica de las herramientas e 
implementos que usan los artesanos en su cotidianidad (cuchilla de corte, cuaderno para conservar el barniz) y contiene además una pieza preparada para aplicar el Barniz y una tela del mismo previamente procesada por los maestros.

Se realizó un testeo con cuatro personas, tres mujeres y un hombre, caracterizadas por estar en el rango de edad de 25 a 40 años, con estudios universitarios y algunos con estudios de maestría. Los asistentes pagaron los materiales del workshop y asistieron durante cuatro horas. El workshop incluyó un pequeño recorrido histórico, el desarrollo de la transformación del Mopa-Mopa en telas de Barniz de Pasto, el conocer los términos usados por los maestros a través de una aplicación de práctica y el diseño de una pequeña artesanía. Uno de los objetivos de los maestros cuando hacen este tipo de acercamiento es, además de contar lo dispendioso del proceso, visibilizar a las familias recolectoras, a los carpinteros, torneros que hacen parte de la cadena de producción del Barniz de Pasto. De esta experiencia se obtuvo retroalimentación importante sobre precios, experiencia y aporte a su conocimiento.

Después de realizado el testeo, se evaluó la experiencia, se contrastó la disposición mínima a pagar presentada por los asistentes con el promedio de la disposición mínima a pagar expresada en la encuesta realizada a los estudiantes de diseño, y con los gastos que los maestros no habían tenido en cuenta antes del desarrollo del workshop. De manera que se adecuaron los precios y los elementos a entregar en el kit a partir de la retroalimentación.

\section{- Métodos}

La investigación fue el resultado de un trabajo de orden cualitativo, se orientó en el interés de comprender e interpretar los contextos que caracterizan la actividad artesanal de la técnica del Barniz de Pasto. El nivel de estudio fue de tipo diagnóstico-propositivo de corte etnográfico, en la medida que buscó comprender la valoración de la artesanía local y proponer, a partir de este análisis, un artefacto plástico sensorial que permita aportar a la salvaguardia de la técnica a través de la valoración artesanal.

El diseño del muestreo fue por conveniencia y por bola de nieve; el tamaño total de la muestra fue de 198 personas que viven en el municipio de Pasto, cuyo rango de edad está entre los 18 y 70 años. Las técnicas utilizadas fueron el muestreo intencional y el muestreo accidental, organizadas de la siguiente forma:

- Muestras variables. Técnica: muestreo intencional. Muestra: 120 personas. Características: personas que viven en la ciudad de Pasto, con un rango de edad entre 18 y 45 años, con estudios secundarios y superiores.

- Muestras con caso tipo. Técnica: muestreo accidental. Muestra: 15 Personas. Características: personas jóvenes que han tomado un taller de acercamiento con el Barniz de Pasto, con un rango de edad entre 21 y 25 años y que estén cursando estudios universitarios.

- Muestras con voluntarios. Técnica: muestreo intencional. Muestra: 63 personas. Características: personas que viven en la ciudad de Pasto en diferentes comunas de la misma. 
Al tener en cuenta que las encuestas se realizaron utilizando muestreo no probabilistico, los resultados de la investigación no pueden ser utilizados en generalizaciones respecto de toda la población.

\section{- Actores sociales y protagonistas de esta investigación}

El trabajo de investigación se realizó en la ciudad de Pasto, Colombia, durante un año y tres meses (abril de 2018 a julio de 2019) y el trabajo de campo se realizó durante diez meses (septiembre de 2018 a julio 2019). Para comprender las dinámicas y las prácticas sociales que giran en torno a la actividad artesanal del Barniz de Pasto Mopa-Mopa, en el desarrollo del proyecto se realizó un piloto con la participación de un taller artesanal de la ciudad de Pasto, en el que trabajan dos maestros artesanos: Ever Segundo Narváez, con más de cuarenta años en el oficio, quien es el padre de Johnattan David Narváez, que lleva más de catorce años en el oficio.

Se eligió este taller artesanal teniendo en cuenta la clasificación artesanal hecha por Eduardo Barroso (2016), en la cual los productos realizados por los maestros Narváez están en la categoría de Artesanía de Referencia Cultural, caracterizada por ser de ascendencia indígena, transmitida de padres a hijos y enfocada a la salvaguardia de la técnica.

Se fundamentó conceptualmente en la propuesta metodológica para la valoración participativa de testimonios de museos y entidades culturales en Colombia (Bastidas \& Vargas, 2013), donde se plantea la valoración a partir de testimonios. El método que utilizó el Instituto Distrital de Patrimonio Cultural de la Alcaldía Mayor de Bogotá, en su libro Bogotá a través del Álbum Familiar (Instituto Distrital de Patrimonio Cultural, 2003), para recolectar imágenes a través de una convocatoria pública que permita construir memoria a partir de imágenes privadas que tienen los ciudadanos en sus álbumes familiares, fue un referente para proponer la metodología de recolección testimonial de esta investigación.

Las imágenes recolectadas y enviadas por los ciudadanos se publican de manera abierta en una plataforma web, que permite identificar, entre otras cosas, los lugares donde hay más o menos artesanías en la ciudad a partir de su ubicación en un mapa abierto bajo los parámetros de Creative Commons.

\section{- Resultados y discusión}

El trabajo artesanal presenta una serie de reflexiones en torno a lo que se considera la valoración del mismo, entendido este oficio como un patrimonio cultural de las regiones donde se desarrolla. La salvaguardia del oficio está enfocada no solamente a la preservación del conocimiento que pasa de generación en generación sino, también, en generar condiciones favorables para que el artesano pueda vivir de su trabajo y que las nuevas generaciones quieran seguir desarrollando su actividad artística.

Esto, de una u otra forma, se fortalece con el valor social dado por la comunidad local, donde cada una de las manifestaciones artísticas remite a aspectos culturales, históricos 
y de representación simbólica, que forman parte de la identidad cultural, la tradición, la memoria viva y es un legado para las futuras generaciones (Balazote \& Rotman, 2006). Así, esta investigación se enfoca en comprender el contexto de las artesanías de referencia cultural, en donde están la mayoría de los talleres artesanales de la región.

Existen grandes desafíos en torno a la protección y salvaguardia del Barniz de Pasto en el escenario social, aunque una gran mayoría de los encuestados reconocieron la técnica y son conocedores del patrimonio. Fueron escasas las personas que dijeron tener artesanías de Barniz de Pasto en sus casas y conocer a profundidad la producción artesanal.

Para comprender los aspectos que motivan la compra y cuál es la percepción ciudadana frente al barniz, se recopilaron testimonios escritos y visuales. Respecto a esto, un joven ciudadano de Pasto, relató:

La devaluación cultural o monetaria de esta artesanía, es grande en comparación a su significado, además no existe una suficiente inversión por parte de entidades gubernamentales para explotar el talento nariñense y darle esa prioridad como un arte que vale la pena comprar y admirar. Haciendo referencia a los comerciantes o artistas, no tienen la suficiente infraestructura (talleres o almacenes) para venderlo de manera masiva (...) por lo general los talleres están en barrios comunes, en los cuales mucha gente desconoce que existen este tipo de artistas. (Testimonio de ciudadano de 22 años, Pasto, 2019)

Se nota así que para algunos ciudadanos jóvenes la problemática es clara y se contrasta efectivamente con los testimonios de personas jóvenes que no tienen barniz. Es el caso de una ciudadana que cuando se le preguntó si conoce algún artesano y si ha comprado artesanías, respondió:

Tengo muy presente al maestro Obando y sus obras, me parece un trabajo muy bonito, pero lo reconozco solamente porque he pasado caminando muchas veces por su taller (...) No se me ha presentado la oportunidad, no lo he pensando ni para decoración, ni para algún detalle a alguien, además se me hace muy costoso. (Testimonio de ciudadana de 23 años, Pasto, 2019)

La visibilización de los artesanos, como en el caso del testimonio anterior, donde la comunidad conoce las obras en su cotidianidad, es un factor importante, al tener en cuenta que los talleres artesanales están ubicados en los barrios residenciales, lejos de los sectores comerciales y gran parte de los ciudadanos desconoce dónde quedan. De esta forma, las acciones que los artesanos realizan, como cursos, exposiciones o videos en redes sociales, son de gran importancia para dar a conocer la técnica a la comunidad. Esto puede ser observado en el testimonio de otro joven ciudadano de Pasto: “Me enteré hace poco tiempo sobre lo que es y cómo se hace el barniz de Pasto. Pude visitar y hablar con el artesano de mopa mopa que se ubica junto a la Casona de Taminango" (Testimonio de ciudadano de 25 años, Pasto, 2019). 
Resultan importantes las relaciones interpersonales y la apertura del artesano a la ciudadanía, de tal forma que, como en el testimonio anterior, se despierte el interés por conocer más sobre la labor artesanal a partir de visitar y hablar directamente con el artesano. Estas prácticas ayudan para que el oficio sea visto de una manera diferente por las nuevas generaciones y se forme, a partir de la empatía, un valor social del trabajo artesanal. El abrir el conocimiento y que los ciudadanos conozcan todo el proceso de creación de la artesanía, así como empatizar con los artesanos, permite generar una valoración de su trabajo a partir del reconocimiento de su labor.

En la mayoría de las respuestas de los encuestados, la percepción recurrente es que es una artesanía de alto costo y es una de las razones que manifiestan para no tener una en casa; así mismo, un alto porcentaje de las personas que ha comprado barniz manifiesta que lo ha hecho para regalar, especialmente a personas extranjeras. Entre los retos que esto supone está el de incrementar el reconocimiento y prestigio del trabajo artesanal del barniz de Pasto, a partir de la valoración social a nivel local de las artesanías. Esto podría verse reflejado también en el incremento del consumo local.

Por otra parte, de los testimonios obtenidos en las encuestas, si se relacionan el contexto actual con lo planteado en un aparte del libro El barniz de Pasto: Testimonio del mestizaje cultural en el sur occidente colombiano, 1542-1777, de Álvaro José Gomezjurado Garzón, se puede inferir lo siguiente, a manera de hipótesis: en el texto de Gomezjurado Garzón (2014, p. 30) se plantea que la comercialización de las piezas decoradas con barniz se da con mayor volumen fuera de la ciudad desde el período colonial. El comercio entre los residentes de Pasto no era tan significativo en la colonia, teniendo en cuenta que Pasto siempre fue una ciudad de paso entre Cartagena y Lima y después entre Quito y Popayán. Esta afirmación se fundamenta en las crónicas que señalan que estas obras eran parte del comercio con Europa. Además, está el hecho de que se encuentren más objetos de la época en museos de Bogotá, Popayán, Lima, Quito y Cuzco, donde residían los funcionarios más importantes, miembros del clero o personas acaudaladas que contaban con posibilidades para tener estas artesanías. De esta forma, existe en el imaginario colectivo la idea de que estas artesanías se compran para regalar y los residentes de Pasto no tienen muchas artesanías en sus casas.

Más adelante Gomezjurado Garzón (2014) afirma:

Según Luis Duque Ramos, al citar a Guamán Poma de Ayala y al Padre Bernabé Cobo, supone que los recipientes de madera decorada podrían ser exclusivos de las elites lo que significa que estos objetos no estaban al alcance de todos, solamente de miembros de las altas esferas de la estructura sociopolítica. (p. 56)

Esto puede suponer que los ciudadanos encuentren actualmente costosas las artesanías de Barniz de Pasto, independientemente de que tengan precios acordes con el mercado. Estos resultados muestran que, para construir el patrimonio, es importante visibilizar las investigaciones históricas sobre el barniz de Pasto como elemento fundamental para reconocer las prácticas culturales. 
La participación ciudadana para construir memoria y patrimonio es fundamental, pues permite tener una apropiación a partir de lo vivencial, como pasa positivamente con el Carnaval Andino de Negros y Blancos. La recopilación de imágenes realizada en esta investigación, permite abrir la información privada, al convertir las fotografías particulares en testimonios documentales abiertos, que pueden aportar a la construcción colectiva de valor social en beneficio de los artesanos y de la ciudad. La plataforma, como resultado del estudio, conformó un Atlas artesanal local, que se aleja del concepto de museo cerrado y elitista. Se planteó como un ejercicio de construcción colectiva, abierto, construido desde lo popular, de lo particular a lo público, desde lo colectivo y participativo, a fin de enmarcarse dentro de lo que se considera común en el concepto de procomún, abordado por Antonio Lafuente (2007).

\section{Referencias Bibliográficas}

Ander-Egg, E. (2005). El proceso de globalización en la cultura. Patrimonio Cultural y Turismo. Cuadernos 13, 143-164. Recuperado de https://www.cultura.gob.mx/ turismocultural/cuadernos/pdf13/articulo14.pdf

Balazote, A. O. \& Rotman, M. B. (julio-diciembre, 2006). Artesanías Neuquinas. Estado y comercialización de artesanías mapuche. Revista Theomai, Red Internacional de Estudios Sobre Sociedad, Naturaleza y Desarrollo, 14, 58-65.

Barroso Neto, E. (30 de marzo de 2016). Diseño y artesanía: Límites de intervención [Mensaje en un blog]. Recuperado de http://artesaniasnamaste.blogspot.com/2016/03/ diseno-y-artesania-limites-de.html

Bastidas, M. F.\&Vargas, M. M. (2013). Propuesta metodológica para la valoración participativa de testimonios de museos y entidades culturales en Colombia. Recuperado de http:// www.museoscolombianos.gov.co/fortalecimiento/comunicaciones/publicaciones/ Documents/Propuesta\%20metodologica\%20para\%20la\%20valoracion.pdf

Estrada Alava, J. C.; Rivera Vallejo, G. A.; Goyes Eraso, S. L. \& Bastidas Mera, E. J. (2008). El Mopa Mopa, tradición artesanal y calidad de vida (1a ed.). Pasto: IUCESMAG.

García Canclini, N. (2000). Culturas híbridas. Estrategias para entrar y salir de la modernidad. México: Grijalbo [u.a.].

Gomezjurado Garzón, Á. J. (2014). El barniz de Pasto: testimonio del mestizaje cultural en el sur occidente colombiano, 1542 - 1777. (Tesis de maestría). Universidad Nacional de Colombia. Medellín. Recuperado de http://www.bdigital.unal.edu. co/12826/1/98389537. 2014.pdf

Instituto Distrital de Patrimonio Cultural (2003). Bogotá vista a través del álbum familiar. Bogotá, DC.: Alcaldía Mayor de Bogotá.

Lafuente, A. (noviembre, 2007). Los cuatro entornos del procomún. Cuadernos de Crítica de la Cultura, (77-78), 15-22. Recuperado de http://digital.csic.es/handle/10261/2746

Malo, C. (noviembre, 2016). La artesanía como forma de vida. Revista Artesanías de América, 75, 10-21. Recuperado de http://documentacion.cidap.gob.ec:8080/bitstream/ cidap/1686/1/La\%20artesan\%C3\%ADa\%20como\%20forma\%20de\%20vida_ Claudio\%20Malo.pdf

Ministerio de Cultura de Colombia. (2019a). El Barniz de Pasto Mopa-Mopa ya es patrimonio 
inmaterial de los colombianos. Recuperado de http://www.mincultura.gov.co/prensa/ noticias/Paginas/El-Barniz-de-Pasto-Mopa-Mopa-ya-es-patrimonio-inmaterial-delos-colombianos.aspx

Ministerio de Cultura de Colombia. (2019b). Plan Especial de Salvaguardia. Conocimientos y técnicas tradicionales asociadas con el Barniz de Pasto, Mopa Mopa de Putumayo y Nariño. Bogotá, DC.: Ministerio de Cultura de Colombia.

Serrano Neira, J. P. (diciembre, 2015). Artesanía y globalización. Revista Artesanías de América, 74, 58-67. Recuperado de http://documentacion.cidap.gob.ec:8080/ bitstream/cidap/1089/1/Artesan\%C3\%ADa\%20y\%20Globalizaci\%C3\%B3nJuan\%20Pablo\%20Serrano.pdf

Throsby, D. (2000). Economic and cultural value in the work of creative artists. In Author (Ed.), Values and Heritage Conservation (pp.26-31). Los Angeles, EE.UU. The Getty Conservation Institute. 


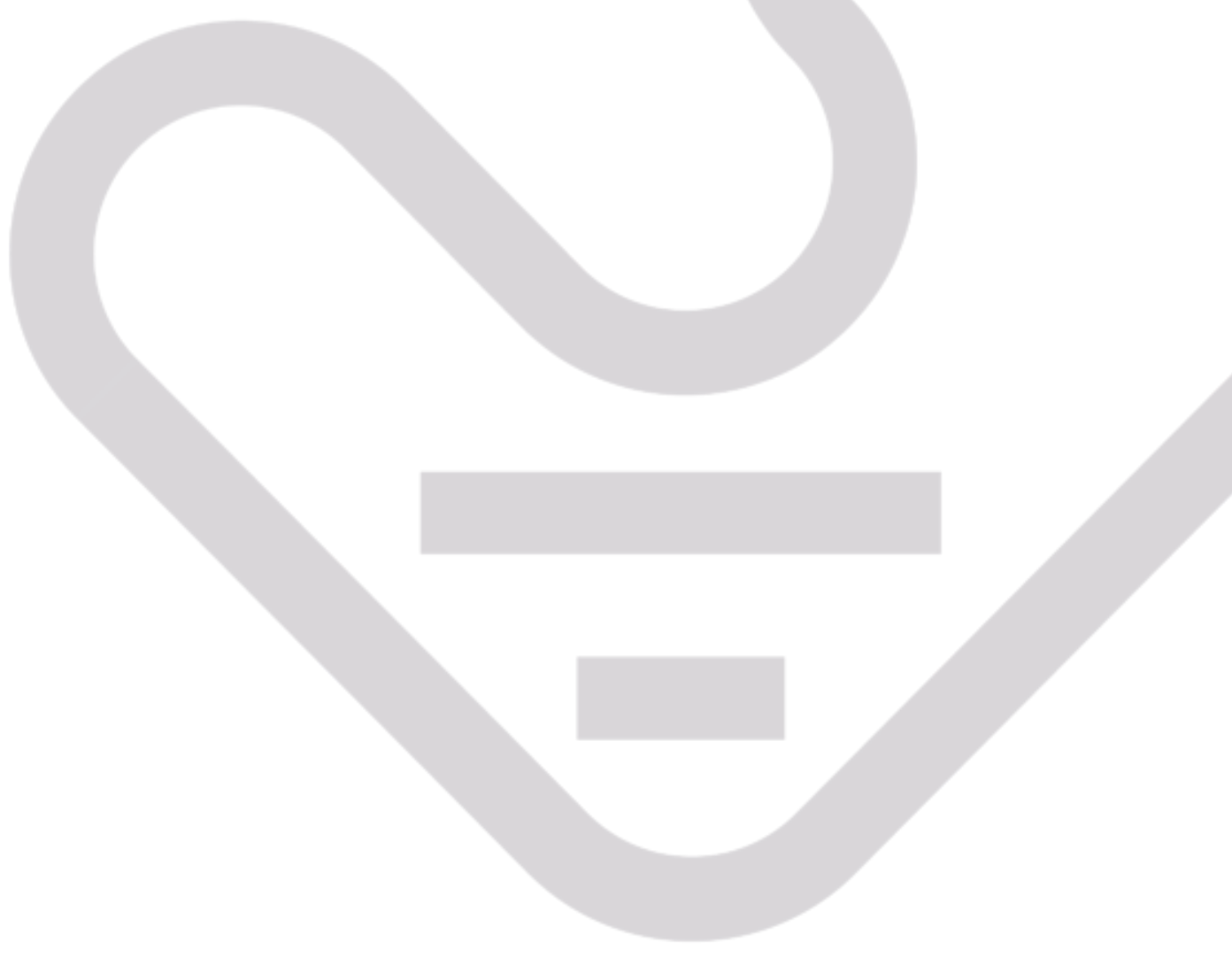

